\title{
Targeting the ENV spike protein of HIV with naturally occurring compounds: an in-silico study for drug designing
}

\author{
S. Sreeram ${ }^{1}\left(\mathbb{D} \cdot\right.$ R. Sathishkumar ${ }^{2}$ (D) P. S. Amritha ${ }^{3}$ (i)
}

Received: 14 July 2021 / Accepted: 14 September 2021

(c) Institute of Korean Medicine, Kyung Hee University 2021

\begin{abstract}
Human Immunodeficiency Virus (HIV) infects human by destroying the immune system. The types of HIV strains HIV-1 and HIV-2, among HIV-1 being more prevalent and considered deadly. Eventually either of the strains leads to disease Acquired Immunodeficiency Syndrome (AIDS). Traditional medicinal plants have a pivotal role in the modern pharmacological process due to their rich composition of secondary metabolites with significant biological activity. Computational tools are gaining momentum as they predict with higher accuracy, robust and provide insight in the interaction of small molecule with the disease target protein. This study was conducted for understanding the interaction mode of Phyto compounds with Env spike proteins of HIV. The compounds are studied for ADME properties and molecular docking using Schrödinger software was performed. From the results, Ethyl gallate was observed with least docking score and higher binding affinity for HIV-ENV protein (4CC8) and Cinnamyl acetate (cis/trans) with HIV-1-ENV protein (6ULC).
\end{abstract}

Keywords ENV protein $\cdot$ Medicinal plants $\cdot$ Molecular docking $\cdot$ ADMET properties $\cdot$ In-silico drug design

\begin{tabular}{ll}
\multicolumn{2}{l}{ Abbreviations } \\
HIV & Human immunodeficiency virus \\
AIDS & Acquired Immune deficiency syndrome \\
Env Protein & Envelop protein \\
ADMET & $\begin{array}{l}\text { Absorption, distribution, metabolism, excre- } \\
\text { tion and toxicity }\end{array}$ \\
RNA & Ribo nucleic acid \\
PDB & Protein data bank \\
CNS & Central nervous system
\end{tabular}

S. Sreeram

sreeramsudhir61@gmail.com

R. Sathishkumar

rsathishkumar_bt@kongunaducollege.ac.in

P. S. Amritha

amritha3097@gmail.com

1 PSG College of Arts and Science, Coimbatore, Tamil Nadu, India

2 Kongunadu Arts and Science College, Coimbatore, Tamil Nadu, India

3 PSGR Krishnammal College for Women, Coimbatore, Tamil Nadu, India

\section{Introduction}

From time immemorial plants or microbes with medicinal activities have been employed in the treatment of various diseases. Traditional herbal products and proper standardization of the botanical drug system with potent scientific evidence can pave the way for creating an efficient therapeutic process (Patwardhan and Mashelkar 2009). Ayurveda clearly emphasizes the importance of natural formulations from herbal for novel drug discovery (Jaiswal and Williams 2017). In Ethiopia, traditional medicine is always related to the curing of disease as well as the protection of human livelihood (Kassaye et al. 2007). Traditional medicine has always been a part of our sustainable living for ages. A rising trend is being observed with drug designing that encompasses the secondary metabolites to target molecules as a therapy for human disorders (Rollinger, Stuppner and Langer 2008).

By incorporating the molecular biology techniques the ability to produce novel natural compounds from microbes or combinational chemistry approaches which provides a platform to establish screening libraries resembling druglike compounds (Harvey 2008). A drug is said to be a failure or ineffective when (a) they don't provide any therapeutic effect against the particular disease (b) they are not safe, in certain setting target identification and validation is the essential step (Hughes et al. 2011). Target can be referred 
to as the place where the drug molecules go attach to a specific biomolecule, it can be proteins, genes, and RNA. A compound is believed to be druggable when it meets all the standard requirements of being a drug in terms of efficacy, safety, and displaying a positive gesture in the clinical trials.

The Human Immunodeficiency Virus (HIV) a human killer attacks the immune system and thereby slowly disintegrating the whole body. Without a strong immune system, the body will be incapable of warding off the foreign particle entering inside the body. It's been three decades since HIV was identified and its effect continues to persist in a large group of people, it is a global epidemic affecting millions of people from all age groups (Piot et al. 2001). It is to be taken into note that the heterosexual mode of transmission is the dominant mode of transmission and it is liable for $85 \%$ of total HIV-1 infections. South Africa remains to be the focal point of disease and the infections continue to prevail (Hayes and Weiss 2006). The white blood cells which form the important part of the immune system will be ravaged by HIV and the class of white blood cells the CD4+ will be destroyed as a result. Complications will arise when a large amount of these blood cells are destroyed whereby putting the body on the verge of immune deficiency and eventually death. AIDS (Acquired Immunodeficiency Syndrome) is the climax stage of infection, at this point, the lives are at stake and cancers seem to occur which is not visible in a healthy person. With a strong base of antiretroviral treatment, AIDS has been demoted to chronic manageable disease from inevitable fatal disease (Simon, Ho and Abdool Karim 2006). To date a permanent cure for HIV/AIDS hasn't been identified, combination antiretroviral therapy is the only solution in practice for the effective treatment of the disease for a lifetime (Mamo et al. 2010). HIV takes around 10-12 years to transform into AIDS, competitive treatment procedures can be done during this period. With the onset of the disease, a broad range of associated diseases will be prevalent in the body, from pneumonia to tumors which will be present in a stage-wise manner in the body (Lucas 2002).

Recently a key protein structure has been visualized which acts as a mediator for HIV to enter into the human immune system and cause dysfunction. The surface protein viral in nature is termed the ENV (PDB id 4CC8). The protein is believed to be a potential target for vaccines amid the dilemma of quick mutations occurring in the ENV. An outer coating of sugar molecules protects the protein from the immune system (Bartesaghi et al. 2013). It is considered that HIV infection commences by the binding of trimeric viral envelop glycoprotein (Env) to CD4 and a co-receptor of the target T-cells (Tran et al. 2012). Another protein HIV-1 Env bound with fab of antibody PG16 (PDB id 6ULC) was also retrieved to be docked with the phytoligands. The goal of vaccine development is to mimic the closed conformation in a desired immunogen (Pan et al. 2020).
In this study, we will be employing the in-silico methods to provide a new therapeutical intervention for HIV/AIDS. The ultimate aim of this study will be focused on developing a drug molecule from the naturally occurring bioactive compounds using computational tools, primarily consisting of molecular docking and ADME analysis.

\section{Materials and methods}

\section{Structure based drug designing}

Structure based drug designing serves a powerful method in identifying new lead compounds when a receptor structure is available (Anderson 2003).

\section{Databases}

In this study 12 number of naturally occurring bioactive compounds from 5 plant species; Corbichonia decumbens, Ocimum sanctum, Syzygium cumini, Momordica charantia, and Terminalia bellerica were selected for docking studies. All the ligand molecules were retrieved from PubChem (https://pubchem.ncbi.nlm.nih.gov/). The target proteins (PDB Id: 4CC8 and 6ULC) was retrieved from the protein data bank (PDB) (https://www.rcsb.org/) (Berman et al. 2000).

\section{Protein preparation}

The proteins were prepared by removing the native auto inducer and all water molecules Hydrogen were added using the templates for the protein residues using Maestro 10.2 version. It is a very essential process as it can rectify if there's any confrontations in the protein structure like missing side chains, and updating the missing residues. The water molecules were removed from the structure and whereby increasing the entropy of the target molecule.

\section{Ligand preparation}

The ligands were converted into 3D structures using the Ligprep tool in maestro Schrodinger version 10.2. The ligand was also geometrically optimized, the 2D sdf files were converted into 3D structures using the ligprep tool.

\section{ADMET profiling}

An account of druggability is very essential while performing a docking study, the ligands were checked for Absorption, distribution, metabolism, excretion and toxicity (ADMET) test. It is a preliminary step in drug preparation. The knowledge on drugs for HIV is very scanty, 
and it is very reasonable to make out more and reduce the cost of treatment as a lot of developing countries can rely on it. 12 compounds successfully scored well in all the ADMET parameters analyzed using Qikprop version 4.4. in the Schrodinger suite (Quikprop module 4.4 2012). Some important parameters like CNS, Blood-barrier coefficient, human blood absorption, Lipinski's rule of three and five were analyzed. The bioactive phyto-compounds which displayed pragmatic result were chosen for the ADME and preferable docking poses has been tabbed for the rationale of docking (Vijayakumar et al. 2018).

\section{Molecular docking}

Molecular docking outlays the ligand's preferred orientation with the target molecule while interacting with each other in forming a highly stable complex. For this purpose, we have employed Maestro v10.2 to conduct the extra precision (XP) docking for speculating the binding affinity, analyzing efficacy of the ligand, and inhibitory constant of ligand against target. In this study, the entire ligand was docked with the target molecule flexibly using the Glide Xtra precision (XP) tool. As a result of successful docking we have obtained better docking scores, poses with accurate hydrophobic contacts between target residues to ligand (Maniam et al. 2017).

\section{Results}

\section{ADME analysis}

In the initial steps of drug discovery process, physio-chemical properties of the small molecules were determined to speculate the key properties of the molecules affecting the biological functions (ADME). In this analysis some 26 key parameters were chosen like, Central Nervous System (CNS), molecular weight, dipole, Total solvent accessible surface area (SASA), total solvent accessible volume, donor and acceptor hydrogen bonds (HB), metabolic reactions, human oral absorption and it's percentage, rule of five $\&$ three, stars, amide, rotor, number of reactive functional groups (rtvFG), FOSA, FISA, PISA, QPlogPoct, QPlogPw, QPlogPo/w, QPPCaco, QPlogBB, QPlogKp, QPlogKhsa. The ADMET results related to the study has been divided into two sections and portrayed in the (Table 1). About 100 compounds selected from which, only a handful of compounds were obeying the required levels of quality controls.

\section{Molecular docking}

Molecular docking methods are currently widespread across the globe in this pandemic era, new approaches are being introduced to bring out a substantial result in the race for an effective drug. A lot of electrostatic energy and van der wall forces (inter-atomic interactions) are participating during the docking analysis. In this context two proteins concerning HIV have been analyzed (i) ENV (4CC8); (ii) HIV-1 ENV (6ULC) with the phytoligands obtained from the plants like Corbichonia decumbens, Ocimum sanctum, Syzygium cumini, Momordica charantia, and Terminalia bellerica.

The docking results of phytoligands with the HIV-ENV protein (4CC8) are mentioned in Table 2. The compound ethyl gallate obtained from Terminalia bellerica showed a very significant $\mathrm{G}$. score (Glide score) of $-9.37 \mathrm{Kcal} / \mathrm{mol}$ than other ligands. The interacting residue are as follows; GLU148 (Fig. 1). Followed by the Glide score of $-8.17 \mathrm{Kcal} / \mathrm{mol}$ was p-Cyanophenyl p-(2- propoxyethoxy) benzoa (Fig. 2) from the herb Corbichonia decumbens. The residues were GLU-148 and ALA-9 with a bond length ( $\AA$ ) of 2.0 and 2.8. Coniferyl alcohol of Syzygium cumini, $1 \mathrm{H}$-Imidazo [1,5-c] thiazole-5,7(6H,7ah)-dio, and Benzenamine, 2,5dichloro-4-nitr of Corbichonia decumbens had a significant g. score of $-7.7,-6.42$, and $-6.12 \mathrm{Kcal} / \mathrm{mol}$ respectively. The residues that interacted with the ligand are GLU-148, TYR-176, GLU-148, VAL-10, and VAL-108. Kaempferol obtained from Syzygium cumini also showed a G. score of $-5.21 \mathrm{Kcal} / \mathrm{mol}$ with residues of VAL- 10 and GLU-148. The last three compounds were $\mathrm{N}$-acetyl-3-methoxyamphetamine Methoxyamphetamine (G. score $-4.7 \mathrm{Kcal} / \mathrm{mol}$ ), N'-isopropylureidoacetic acid (G. score -3.98), and Cinnamyl acetate, (cis/ Trans) (G. score $-4.15 \mathrm{Kcal} / \mathrm{mol}$ ) of the plants Ocimum sanctum and Syzygium cumini.

Similarly, the docking results of phytoligands with HIVENV protein (6ULC) are mentioned in Table 3. This was the second spike protein considered for the docking studies, and the results obtained were comparatively appreciable. The compound cinnamyl acetate showed a G. score of $-9.67 \mathrm{Kcal} / \mathrm{mol}$ (Fig. 3) with residues interacted such as TRP-69. The compound was obtained from the plant Syzygium cumini. The other compounds were 2, 5-dihydroxybenzyl alcohol 3 (G. score $-9.32 \mathrm{Kcal} / \mathrm{mol}$ ) (Fig. 4) with residue TRP-69 and ethyl gallate (G. score $-7.15 \mathrm{Kcal} /$ mol) with residue LEU-261, VAL-254, and GLU-482 from the plants Corbichonia decumbens and Terminalia bellerica. From the medicinal herb Corbichonia decumbens, compounds such as 2,4,6,8- Tetraazabicyclo[3.3.0] oct an-3-one (G. score $-6.6 \mathrm{Kcal} / \mathrm{mol}$ ), residues LEU-261, LEU-261; p-Cyanophenyl p-(2- propoxyethoxy) benzoa (G. score $-5.15 \mathrm{Kcal} / \mathrm{mol}$ ), residues ASN-262, ARG252; 1H-Imidazo[1,5-c]thiazole-5,7(6H,7ah)- dio (G. score $-5.21 \mathrm{Kcal} / \mathrm{mol})$, residues ASN-262, ASN-377 were obtained. One compound phenylalanine (G. score $-6.2 \mathrm{Kcal} /$ mol) residues LEU-261, LEU-261, and VAL-254 from the plant Momordica charantia and two compounds N-acetyl3-methoxyamphetamine Methoxyamphetamine (G. score -4.96) residue LEU-261 and N'-isopropylureidoacetic acid 


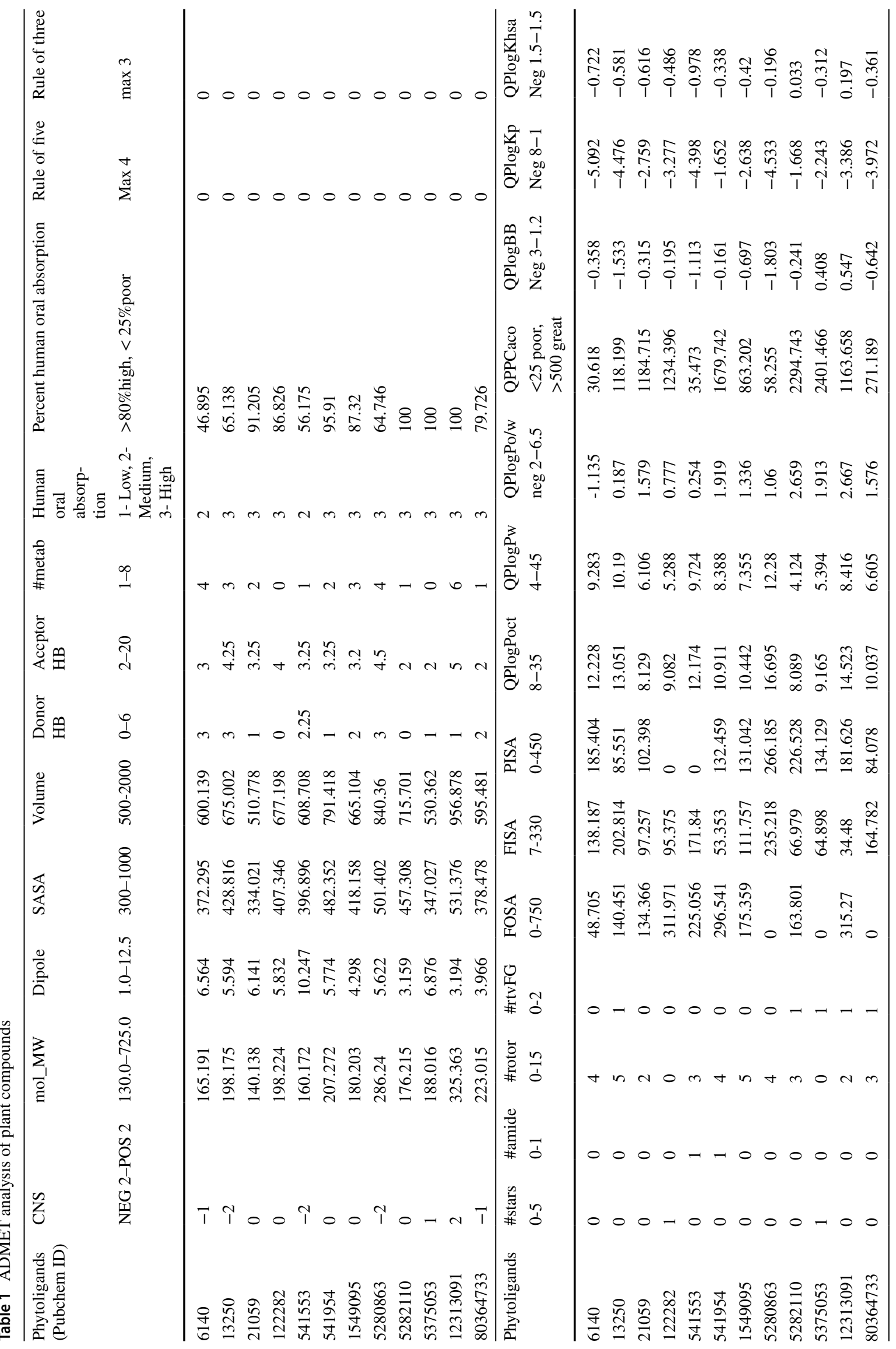


Table 2 Molecular docking analysis of phyto compounds with HIV-ENV (4CC8) protein

\begin{tabular}{|c|c|c|c|c|c|}
\hline Name of plant & Name of compound & $\begin{array}{l}\text { G. Score } \\
\text { (Kcal/ } \\
\text { mol) }\end{array}$ & Residues interacted & Bond length & No. of bonds \\
\hline Terminalia bellerica & Ethyl gallate & -9.37 & GLU-148 (H-O) & 2.1 & 1 \\
\hline Corbichonia decumbens & p-Cyanophenyl p-(2- propoxyethoxy)benzoa & -8.17 & $\begin{array}{l}\text { GLU-148 (H-O) } \\
\text { ALA -9 }(\mathrm{H}-\mathrm{O})\end{array}$ & $\begin{array}{l}2 \\
2.8\end{array}$ & 2 \\
\hline Syzygium cumini & Coniferyl alcohol & -7.7 & $\begin{array}{l}\text { GLU-148 (O-H) } \\
\text { TYR } 176(\mathrm{H}-\mathrm{O})\end{array}$ & $\begin{array}{l}2.1 \\
2.5\end{array}$ & 2 \\
\hline Corbichonia decumbens & 1H-Imidazo[1,5-c]thiazole-5,7(6H,7ah)- dio & -6.42 & GLU $148(\mathrm{H}-\mathrm{O})$ & 2.2 & 1 \\
\hline Corbichonia decumbens & Benzenamine, 2,5- dichloro-4-nitr & -6.12 & $\begin{array}{l}\text { VAL } 10(\mathrm{H}-\mathrm{O}) \\
\text { VAL } 108(\mathrm{H}-\mathrm{O})\end{array}$ & $\begin{array}{l}2 \\
2\end{array}$ & 2 \\
\hline Syzygium cumini & Kaempferol & -5.21 & $\begin{array}{l}\text { VAL } 10(\mathrm{H}-\mathrm{O}) \\
\text { GLU } 148(\mathrm{H}-\mathrm{O})\end{array}$ & $\begin{array}{l}2 \\
2\end{array}$ & 2 \\
\hline Ocimum sanctum & $\begin{array}{l}\text { N-acetyl-3-methoxyamphetamine Methoxyampheta- } \\
\text { mine }\end{array}$ & -4.7 & GLU $148(\mathrm{H}-\mathrm{O})$ & 2 & 1 \\
\hline Syzygium cumini & Cinnamyl acetate, (cis/trans) & -4.15 & TYR 176 (O-H) & 3.1 & 1 \\
\hline Ocimum sanctum & N'-isopropylureidoacetic acid & -3.98 & $\begin{array}{l}\text { GLY } 106(\mathrm{H}-\mathrm{O}) \\
\text { GLY } 106(\mathrm{H}-\mathrm{O}) \\
\text { GLU } 89(\mathrm{H}-\mathrm{O})\end{array}$ & $\begin{array}{l}2.3 \\
1.9 \\
1.6\end{array}$ & 3 \\
\hline
\end{tabular}
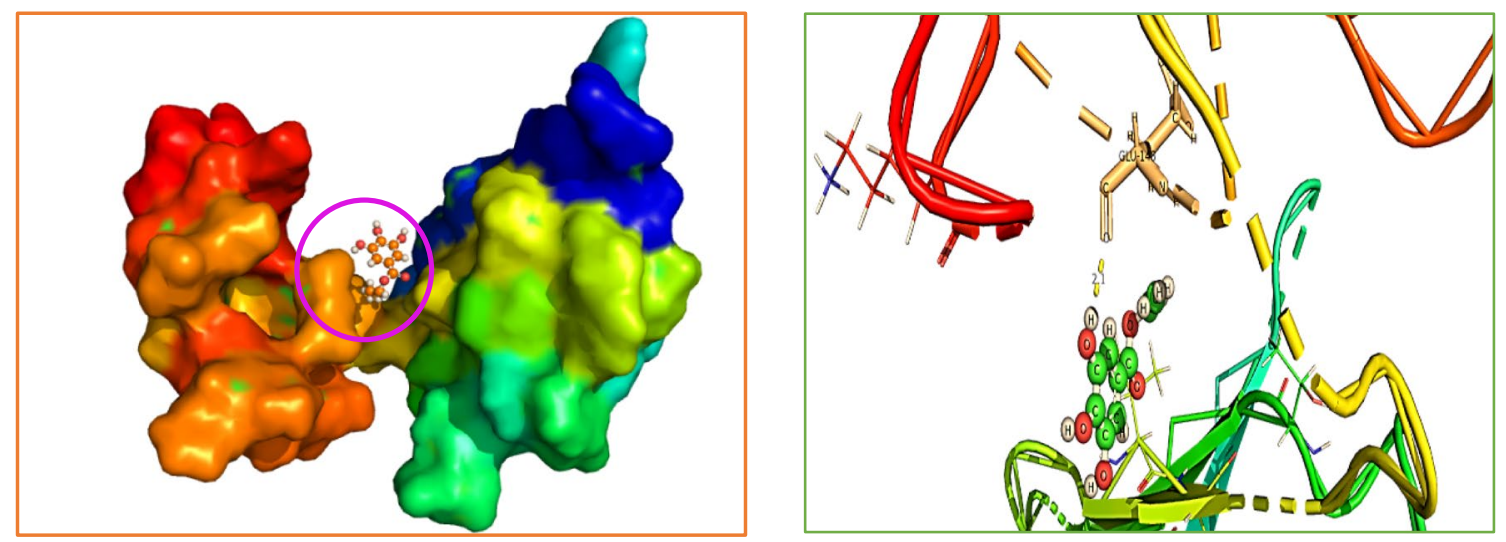

Fig. 1 Interaction of Phytoligand Ethyl gallate with the HIV-ENV (4CC8) protein having a least Glide score of $-9.37 \mathrm{Kcal} / \mathrm{mol}$ extracted from the plant Terminalia bellerica indicating a suitable drug candidate molecule

(G. score $-4.08 \mathrm{Kcal} / \mathrm{mol}$ ) residues LEU-261, GLU-482, and GLU-482 from the plant Ocimum sanctum were successfully docked with the protein.

\section{Discussion}

From the beginning, the proposal of work was based on the laboratory needs, but due to the sudden unexpected pandemic we couldn't carry out the wet labs, enforcing us from a complex to a facile work. In future, these could be executed in laboratories to substantiate the existing data. Therefore, the phytoligands from the different plants are collected from the reputed unbiased journal articles.
The most important part of drug discovery and development is conducting DMPK (Drug Metabolism and Pharmacokinetics) studies, also known as ADMET studies. It is believed that ADME shows the toxicity of small molecules (Pajouhesh and Lenz 2005; Mondal et al. 2009). With the advent of drug discovery, in-silico works have predominantly seen an upsurge with the assessment of drug efficacy and toxicity levels. ADMET has been given utmost importance right from the beginning of drug discovery using in-silico techniques (Selick, Beresford, and Tarbit 2002). Molecular docking is a common method to assess the protein-ligand interaction thereby predicting an efficient binding of the ligand with the target protein molecule. Not only protein-ligand binding, but we can also carry 


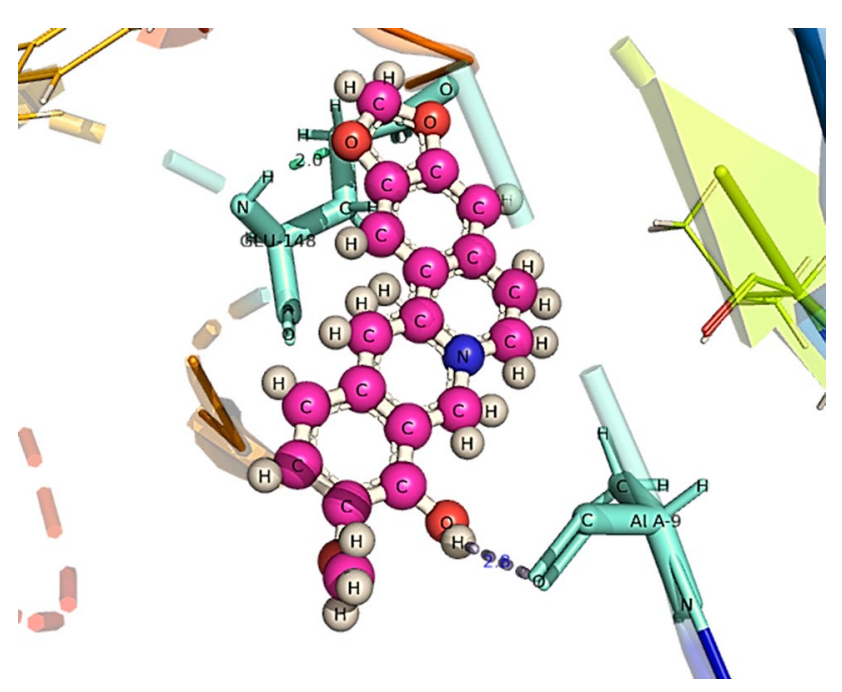

Fig. 2 Interaction of Phyto ligand p-Cyanophenyl p-(2- propoxyethoxy)benzoa with the HIV-ENV (4CC8) protein with the second least Glide score of $-8.17 \mathrm{Kcal} / \mathrm{mol}$ extracted from the plant Corbichonia decumbens

out protein-protein, DNA-protein, DNA-ligand interactions (Morris and Lim-Wilby 2008). The binding affinity of a molecule to target is reckoned upon the contributions from various factors such as entropy, de salvation, and flexibility of receptor molecule to the ligand.

Secondary metabolites are defined as a heterogeneous group of natural metabolic products that are not essential for the vegetative growth of the producing organisms. The multitude of secondary metabolite secretions is harvested by humankind to improve their health (antibiotics, enzyme inhibitors, immunomodulators, antitumor agents, and growth promotors of animals and plants), widen the pyramid of healthy nutrition (pigments and nutraceuticals), and hence impacting economics our society in a certain positive way. They are a source of antibiotics (Demain and Fang 2000). Plants are rich in a wide variety of secondary metabolites, such as tannins, terpenoids, alkaloids, and flavonoids, which have been found to have in vitro antimicrobial properties (Rodbey et al. 2000).

Bioactive compounds from medicinal plants are very well utilized for their therapeutic purpose, the preliminary docking studies form a base for these kinds of works (Srinivasan et al. 2011). Most of the compounds studied fall under the class Flavonoids, Tannins, Anthocyanins- Anthocyanidins. Flavonoids are a group of plant metabolites thought to provide health benefits through cell signaling pathways and antioxidant effects. These molecules are found in a variety of fruits and vegetables (Kim et al. 2003). The flavonoids are recognized to function essentially in the management of disorders and diseases in humans (Husain et al. 2017). One flavonoid called quercetin can help to alleviate eczema, sinusitis, asthma, and hay fever. Some studies have shown that flavonoid intake is inversely related to heart disease, with these molecules inhibiting the oxidation of low-density lipoproteins and therefore reducing the risk of atherosclerosis

Table 3 Molecular docking analysis of phyto compounds with the HIV-1-ENV (6ULC) protein

\begin{tabular}{|c|c|c|c|c|c|}
\hline Name of plant & Name of compound & $\begin{array}{l}\text { G. Score @ } \\
(\mathrm{Kcal} / \mathrm{mol})\end{array}$ & Residues interacted & Bond length & No. of bonds \\
\hline Syzygium cumini & Cinnamyl acetate, (cis/trans) & -9.67 & TRP $69(\mathrm{O}-\mathrm{H})$ & 2 & 1 \\
\hline Corbichonia decumbens & 2,5-dihydroxybenzyl alcohol 3 & -9.32 & TRP $69(\mathrm{O}-\mathrm{H})$ & 2 & 1 \\
\hline Terminalia bellerica & Ethyl gallate & -7.15 & $\begin{array}{l}\text { LEU } 261(\mathrm{O}-\mathrm{H}) \\
\text { VAL } 254(\mathrm{H}-\mathrm{O}) \\
\text { GLU } 482(\mathrm{H}-\mathrm{O})\end{array}$ & $\begin{array}{l}2 \\
2.3 \\
2.1\end{array}$ & 3 \\
\hline Corbichonia decumbens & 2,4,6,8- Tetraazabicyclo[3.3.0]oct an-3-one & -6.6 & $\begin{array}{l}\text { LEU } 261(\mathrm{O}-\mathrm{H}) \\
\text { LEU } 261(\mathrm{O}-\mathrm{O})\end{array}$ & $\begin{array}{l}1.9 \\
3.3\end{array}$ & 2 \\
\hline Momordica charantia & Phenylalanine & -6.2 & $\begin{array}{l}\text { LEU } 261(\mathrm{O}-\mathrm{H}) \\
\text { LEU } 261(\mathrm{H}-\mathrm{O}) \\
\text { VAL } 254(\mathrm{O}-\mathrm{H})\end{array}$ & $\begin{array}{l}2.4 \\
2.6 \\
2.1\end{array}$ & 3 \\
\hline Corbichonia decumbens & p-Cyanophenyl p-(2- propoxyethoxy)benzoa & -5.15 & $\begin{array}{l}\text { ASN } 262(\mathrm{O}-\mathrm{H}) \\
\text { ARG } 252(\mathrm{O}-\mathrm{H})\end{array}$ & $\begin{array}{l}2.4 \\
2.5\end{array}$ & 2 \\
\hline Corbichonia decumbens & 1H-Imidazo[1,5-c]thiazole-5,7(6H,7ah)- dio & -5.21 & $\begin{array}{l}\text { ASN } 262(\mathrm{~N}-\mathrm{H}) \\
\text { ASN } 377(\mathrm{H}-\mathrm{O})\end{array}$ & $\begin{array}{l}2.6 \\
1.9\end{array}$ & 2 \\
\hline Ocimum sanctum & $\begin{array}{l}\text { N-acetyl-3-methoxyamphetamine Methoxyampheta- } \\
\text { mine }\end{array}$ & -4.96 & LEU $261(\mathrm{O}-\mathrm{H})$ & 1.7 & 1 \\
\hline Ocimum sanctum & N'-isopropylureidoacetic acid & -4.08 & $\begin{array}{l}\text { LEU } 261(\mathrm{H}-\mathrm{O}) \\
\text { GLU } 482(\mathrm{H}-\mathrm{O}) \\
\text { GLU } 482(\mathrm{H}-\mathrm{O})\end{array}$ & $\begin{array}{l}1.7 \\
2.6 \\
2.1\end{array}$ & 3 \\
\hline
\end{tabular}



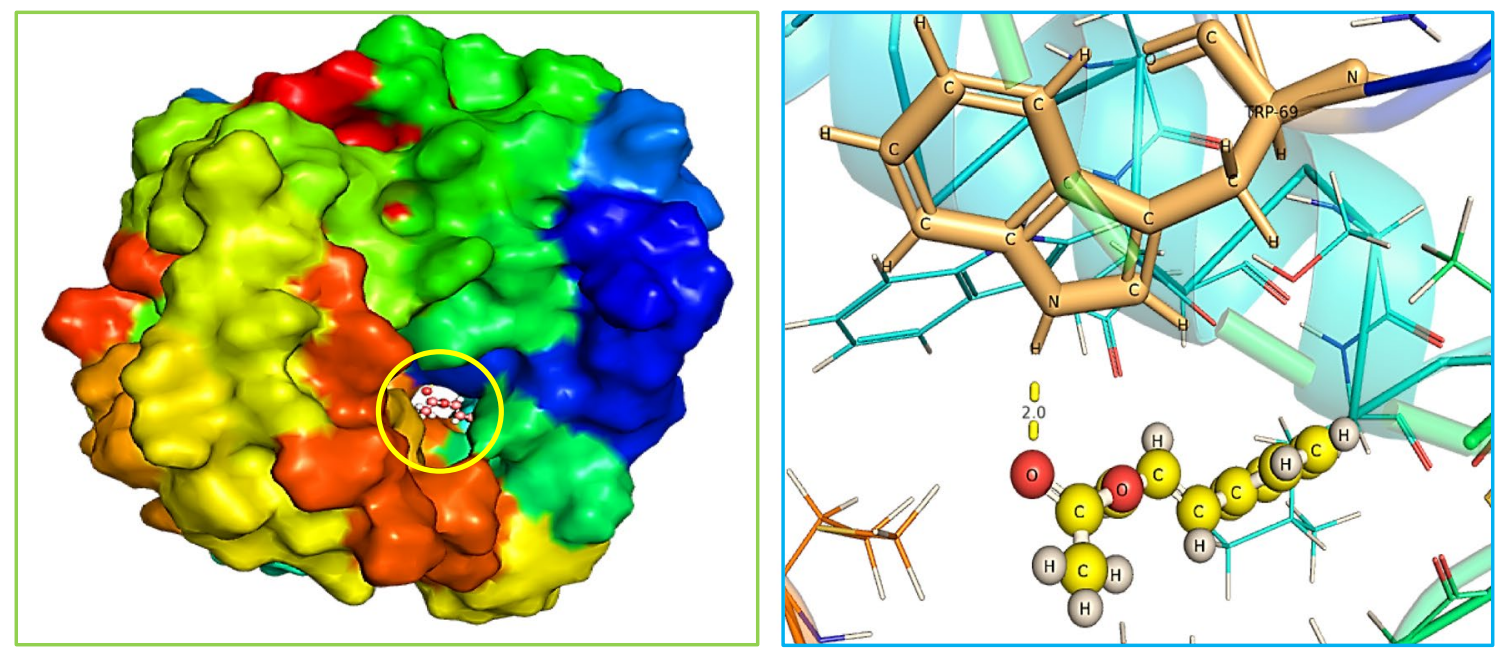

Fig. 3 Interaction of Phytoligand Cinnamyl acetate, (cis/ trans) with HIV-1-ENV protein (6ULC) extracted from plant Syzygium cumini with the least Glide score of $-9.67 \mathrm{Kcal} / \mathrm{mol}$ suggesting a new drug candidate molecule

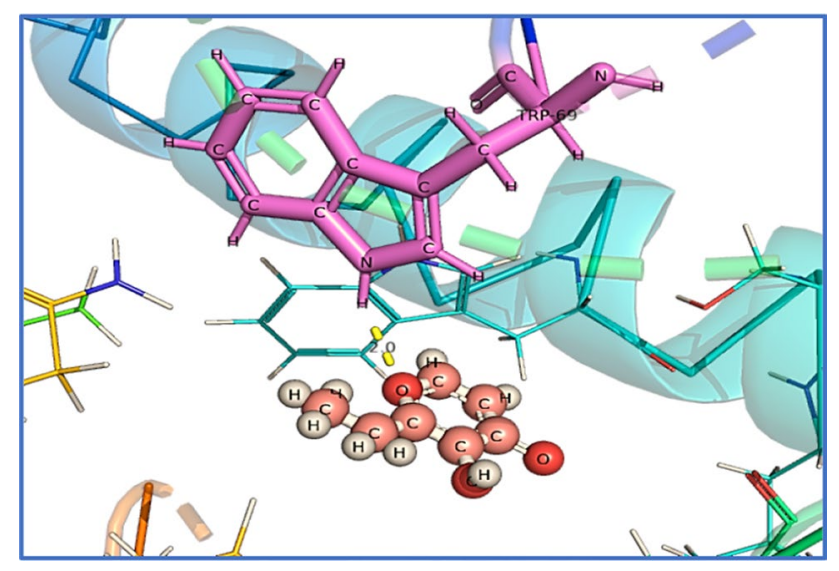

Fig. 4 Interaction of Phyto ligand 2,5-dihydroxybenzyl alcohol 3 with HIV-1-EVN protein (6ULC) with the second least Glide score of $-9.32 \mathrm{Kcal} / \mathrm{mol}$ extracted from Terminalia bellerica

developing (Pasetto, Pardi and Murata 2014). Tannin, also called tannic acid, is a class of phenolic compounds in woody flowering plants that are important deterrents to herbivores and have several industrial applications. Because of its styptic and astringent properties, tannin has been used to treat tonsillitis, pharyngitis, hemorrhoids, and skin eruptions; it has been administered internally to check diarrhea and intestinal bleeding and as an antidote for metallic, alkaloidal, and glycosidic poisons, with which it forms insoluble precipitates (Encyclopedia Britannica 2021). On the other hand, plant anthocyanins have been widely studied for their medicinal values. Anthocyanins are commonly found in flowers and the fruits of many plants. Most of the red, purple, and blue-colored flowers contained anthocyanins. Red flowers are red hibiscus, red rose, red pineapple sage, red clover, and pink blossom. These red flowers are edible. Blue, red, and purple-colored pigments extracted from flowers, fruits, and vegetables are traditionally used as dye and food colorants. Besides being used as natural colorants, some of the anthocyanin-rich flowers and fruits have been traditionally used as medicine to treat various diseases Anthocyanins possess antidiabetic, anticancer, anti-inflammatory, antimicrobial, and anti-obesity effects, as well as prevention of cardiovascular diseases (CVDs) (Khoo et al. 2017).

Terminalia bellerica is a type of medicinal plant abundantly found in the Indian Subcontinent, Sri Lanka, Bangladesh, etc. There are a wide variety of constituents which serves as an antioxidant, antimicrobial, antidiarrheal, anticancer, antipyretic agent (Anindita, Sikha, and Biswajit 2016). Ethyl gallate is a food additive denoted by the E313, it is obtained by the formal condensation of gallic acid with ethanol. It is also present naturally in a variety of plant sources including walnuts, etc. It is well known for its antioxidant and anticancer properties (Mohan, Thiagarajan, and Chandrasekaran 2017). Traditionally $C$. decumbens leaves are used as an herbal alternative for healing various diseases such as to treat gonorrhea and kidney stones. Root paste can be consumed orally for treating yellow and white jaundice. Similarly, the crude extract shows antioxidant, anti-inflammatory, and antiulcer activities (Arora and Saini 2018). Syzgium cumini is an evergreen tropical tree, also known as Malabar plum, Java Plum, or even jambolana which has been used against dysentery, inflammation, and diabetes mellitus (Shafi et al. 2002). The plant is a rich repository of secondary metabolites such as anthocyanins, glucoside, ellagic acid, isoquercetin, kaemferol, and myricetin, and the plant as a whole is medicinally effective (Ayyanar and SubashBabu 2012). Kaempferol is well known for its medicinal 
activity, it is said to provide the body with the best antioxidant defense system against free radicals. It regulates apoptosis, angiogenesis, inflammation, and metastasis (Chen and Chen 2013). Momordica Charantia, commonly known as bitter gourd, karela, or balsam pear whose fruits are used for diabetic treatment, anticancer, anti-inflammation, antiviral, and has cholesterol-lowering effects. The fruits, stems, leaves, as well as roots of bitter melon aids in the treatment of ailments such as hyperlipidemia, digestive disorders, microbial infections, and menstrual problems (Baby and Jini 2013). Different parts of the Ocimum sanctum are used since traditional systems for the treatment of skin diseases, arthritis, asthma, malaria, and many more. Tulsi possesses a wide variety of therapeutic uses such as antidiabetic, antimicrobial, hepatoprotective, cardioprotective, antispasmodic, analgesic actions (Prakash and Neelu 2005).

\section{Conclusion}

The study focused on HIV/AIDS a sexually transmitted viral infection that affects the human immune system. Antiretroviral therapy is the only mode of effective treatment available even after 30 years of onset of disease. The treatments procedure currently followed are highly expensive and cannot be taken by a common man. Here, Phyto-compounds are predicted with significant interactions with target protein indicating the potency in the treatment. Ethyl gallate showed least docking score with the protein HIV-ENV (4CC8). Followed by Cinnamyl acetate (cis/trans) from Syzygium cumini with the target protein HIV-1-ENV (6ULC). Therefore, it is summarized that Phyto-compounds have a better drug candidate for HIV/AIDS. It is to be noted that invitro \& in-vivo assessment will be essential and looking forward that these computational results would prove to be helpful in successful drug development.

\begin{abstract}
Acknowledgement The authors are thankful to the head and staff of the department of Biotechnology, Kongunadu Arts and Science College, Coimbatore for allowing to carry out the work as part of the completion of the PG Diploma program in Bioinformatics.
\end{abstract}

Author's contribution RS has done the bioinformatics part of ADME, molecular docking studies and reviewed the manuscript. SS has drafted the manuscript, collected the articles and PSA done the PyMOL visualizations.

Funding No funding was received for conducting this study.

\section{Declarations}

Ethical statement This article does not contain any studies involving animals performed by any of the authors. This article does not contain any studies involving human participants performed by any of the authors.
Conflict of interest S. Sreeram has no conflict of interest. R. Sathishkumar has no conflict of interest. P. S. Amritha has no conflict of interest.

\section{References}

Anderson AC (2003) The process of structure-based drug design. Chem Biol 10(9):787-797. https://doi.org/10.1016/j.chembiol. 2003.09.002

Arora S, Saini M (2018) Anatomical studies on Corbichonia decumbens (Forssk.) Exell, an important medicinal herb from Rajasthan. J Drug Deliv Ther 8(5):228-231

Ayyanar M, Subash-Babu P (2012) Syzygium cumini (L.) Skeels: a review of its phytochemical constituents and traditional uses. Asian Pac J trop biomed. 2(3):240-246. https://doi.org/10.1016/ S2221-1691(12)60050-1

Bartesaghi A et al (2013) Prefusion structure of trimeric HIV-1 envelope glycoprotein determined by cryo-electron microscopy. Nat Struct Mol Biol 20(12):1352-1357. https://doi.org/10.1038/nsmb. 2711

Berman HM, Westbrook J, Feng Z, Gilliland G, Bhat TN, Weissig H, Shindyalov IN, Bourne PE (2000) The protein data bank. Nucl Acids Res 28(1):235-242

Britannica, The Editors of Encyclopaedia. "Tannin". Encyclopedia Britannica, 27 Jan. 2021, https://www.britannica.com/science/tannin. Accessed 29 August 2021.

Chen AY, Chen YC (2013) A review of the dietary flavonoid, kaempferol on human health and cancer chemoprevention. Food Chem 138(4):2099-2107. https://doi.org/10.1016/j.foodchem.2012.11. 139

Demain AL, Fang A (2000) The Natural Functions of Secondary Metabolites. Adv. Biochem. Engin. Biotechnol. 69:1-39. https:// doi.org/10.1007/3-540-44964-7_1

Harvey AL (2008) Natural products in drug discovery. Drug Discov Today 13(19-20):894-901. https://doi.org/10.1016/j.drudis.2008. 07.004

Hayes R, Weiss H (2006) Understanding HIV epidemic trends in Africa. Sci 311(5761):620-621. https://doi.org/10.1126/science. 1124072

Hughes JP et al (2011) Principles of early drug discovery. Br J Pharmacol 162(6):1239-1249. https://doi.org/10.1111/j.1476-5381. 2010.01127.x

Husain FM, Ahmad I, Al-thubiani AS, Abulreesh HH, AlHazza IM, Aqil F (2017) Leaf extracts of Mangifera indica L. inhibit quorum sensing-regulated production of virulence factors and Bioflm in test bacteria. Front Microbiol. https://doi.org/10.3389/fmicb. 2017.00727

Jaiswal YS, Williams LL (2017) A glimpse of Ayurveda-the forgotten history and principles of Indian traditional medicine. J Tradit Complement Med 7(1):50-53. https://doi.org/10.1016/j.jtcme. 2016.02.002

Kassaye $\mathrm{K}$ et al (2007) A historical overview of traditional medicine practices and policy in Ethiopia. Ethiop J Health Dev 20(2):127134. https://doi.org/10.4314/ejhd.v20i2.10023

Khoo HE, Azlan A, Tang ST, Lim SM (2017) Anthocyanidins and anthocyanins: colored pigments as food, pharmaceutical ingredients, and the potential health benefits. Food Nutr Res 61(1):1361779. https://doi.org/10.1080/16546628.2017.1361779

Kim D, Jeong S, Weon L, Chang Y (2003) Antioxidant capacity of phenolic phytochemicals from various cultivars of plums. Food Chem 81:321-326. https://doi.org/10.1016/S0308-8146(02)00423-5

Lucas S (2002) The pathology of HIV infection. Lepr Rev 73(1):64-71. https://doi.org/10.47276/1r.73.1.64 
Mamo T et al (2010) Emerging nanotechnology approaches for HIV/ AIDS treatment and prevention. Nanomedicine 5(2):269-285. https://doi.org/10.2217/nnm.10.1

Maniam GP et al (2017) Homology modeling and molecular docking studies on Type II diabetes complications reduced PPAR $\gamma$ receptor with various ligand molecules Homology modeling and molecular docking studies on Type II diabetes complications reduced PPARg receptor with various ligand molecule. Biomed Pharmacother 92:528-535. https://doi.org/10.1016/j.biopha.2017.05.077

Mondal SK et al (2009) Determination of drug-like properties of a novel antileishmanial compound: In vitro absorption, distribution, metabolism, and excretion studies. Indian J Pharmacol 41(4):176181. https://doi.org/10.4103/0253-7613.56075

Morris GM, Lim-Wilby M (2008) Molecular docking. In: Kukol A (ed) Molecular Modeling of proteins. Methods molecular biology. Humana Press, Totowa, pp 365-382

Pajouhesh H, Lenz GR (2005) Medicinal chemical properties of successful central nervous system drugs. NeuroRX 2(4):541-553. https://doi.org/10.1602/neurorx.2.4.541

Pan J et al (2020) Cryo-EM Structure of Full-length HIV-1 Env Bound With the Fab of Antibody PG16. J Mol Biol 432(4):1158-1168. https://doi.org/10.1016/j.jmb.2019.11.028

Pasetto S, Pardi V, Murata RM (2014) Anti-HIV-1 activity of flavonoid myricetin on HIV-1 infection in a dual-chamber in vitro model. PLoS One 9(12):e115323. https://doi.org/10.1371/journal.pone. 0115323

Patwardhan B, Mashelkar RA (2009) Traditional medicine-inspired approaches to drug discovery: can Ayurveda show the way forward? Drug Discov Today 14(15-16):804-811. https://doi.org/10. 1016/j.drudis.2009.05.009

Piot P et al (2001) The global impact of HIV/AIDS. Nature 410(6831):968-973. https://doi.org/10.1038/35073639

Prakash P, Gupta N (2005) Therapeutic uses of Ocimum sanctum with a note on eugenol and its pharmacological uses. Indian J Physiol Pharmacol 49(2):125-131

Quikprop, module 4.4 (2012) Schrodinger suite, New York

Rollinger JM, Stuppner H, Langer T (2008) Virtual screening for the discovery of bioactive natural products. In: Petersen F, Amstutz
R (eds) Natural compounds as drugs Volume I Progress in drug research. Birkhäuser, Basel, pp 211-249

Selick HE, Beresford AP, Tarbit MH (2002) The emerging importance of predictive ADME simulation in drug discovery. Drug Discov. Today. 7(2):109-116. https://doi.org/10.1016/S1359-6446(01) 02100-6

Shafi PM, Rosamma MK, Jamil K, Reddy PS (2002) Antibacterial activity of Syzygium cumini and Syzygium travancoricum leaf essential oils. Fitoterapia 73(5):414-416. https://doi.org/10.1016/ S0367-326X(02)00131-4

Mohan S, Thiagarajan K, Chandrasekaran R (2017) Evaluation of ethyl gallate for its antioxidant and anticancer properties against chemical-induced tongue carcinogenesis in mice. Biochem J 474(17):3011-3025. https://doi.org/10.1042/BCJ20170316

Simon V, Ho DD, Abdool Karim Q (2006) HIV/AIDS epidemiology, pathogenesis, prevention, and treatment. Lancet 368(9534):489504. https://doi.org/10.1016/S0140-6736(06)69157-5

Srinivasan P, Sudha A, Hameed AS, Kumar SP, Karthikeyan M (2011) Screening of medicinal plant compounds against NS5B polymerase of hepatitis $\mathrm{C}$ virus (HCV) using molecular docking studies. J Pharm Res 4(1):136-140

Tran EEH et al (2012) Structural mechanism of trimeric HIV-1 envelope glycoprotein activation. PLoS Patho 8(7):37. https://doi.org/ 10.1371/journal.ppat.1002797

Vijayakumar S et al (2018) Novel ligand-based docking; molecular dynamic simulations; and absorption, distribution, metabolism, and excretion approach to analyzing potential acetylcholinesterase inhibitors for Alzheimer's disease. J Pharm Anal 8(6):413-420. https://doi.org/10.1016/j.jpha.2017.07.006

Publisher's Note Springer Nature remains neutral with regard to jurisdictional claims in published maps and institutional affiliations. 